\title{
P01-260
}

\section{RELIGIOUS MORAL BELIEFS AND DEPRESSIVENESS AMONGST WAR VETERANS IN BOSNIA AND HERZEGOVINA AFTER WAR 1992-95}

\section{Hasanović, I. Pajević}

Psychiatry Department, University Clinical Centre TuzlaClinical Centre Tuzla, School of Medicine University of Tuzla, Tuzla, BosniaHerzegovina

Aim: To determine association of religious moral beliefs and depressiveness of war veterans twelve years after Bosnia-Herzegovina war 1992-95, finished.

Methods: The sample consists of 99 male war veterans aged $41.7 \pm 6.8$ years, who were inpatients $(n=50)$ in Department of Psychiatry in Tuzla with clinically presented depression and those who were observed as healthy regarding results of previous psychological testing $(n=49)$. Groups were equalized by educational level (secondary school), behavioral characteristics, family structure, and level of exposure to war trauma. Subjects were assessed with regard to the level of belief in some basic ethical principles that arise from religious moral values. The score of religious moral belief index was used to compare two groups of subjects. For sample selection the measuring instruments were used to assess the religious, moral and social profile of subject. We applied the Bosnia-Herzegovina versions of Hopkins Symptom Checklist - 25 (HSCL-25) for measuring of depression symptoms and Harvard Trauma Questionnaire (HTQ) for measuring of trauma experiences.

Results: The score of the religious moral belief index was significantly negatively correlated to the score of depressiveness (Pearson's $r=-0.289, \mathrm{P}=0.004$ ).

Conclusions: A higher index of religious moral beliefs amongst war veterans was associated with lower level of depressiveness. In this way, it helps protection, development and socialization of the war veterans after surviving severe war traumatization, leading to the mental health stability. 